Cross and Metsätähti (private operator). The units are e.g. in disused apartment houses, elderly homes or schools: tents have not been needed. Since the EHUs has been set up urgently, the hygienic and health facilities are not optimal. The major infectious risks in crowded facilities were considered to be tuberculosis and measles. Common diseases, e.g. influenza and acute gastroenteritis, would be largely transmitted in the circumstances. Also parasites, such as scabies, were likely to be seen.

Effects/changes The staff was informed and offered the recommended vaccines. Guidelines for infectious diseases were set. A nurse and a doctor visited in the EHUs in regular basics, and emergency cases were referred to hospital. The people with symptoms of tuberculosis were screened. All the children and pregnant women were offered the same health care services as Finnish citizens.

Conclusions As of January 2016, no imminent health risks have been seen. By the conference we will have some data available of the process and health in our emergency centres.

\section{Self-Harm and Drunk Driving}

\section{MON W AP 3}

\section{INJURIES AMONG UNIVERSITY STUDENTS - SELF-HARM AND DRUNK DRIVING}

${ }^{1}$ Emma Honkala, ${ }^{1}$ Tjede Funk, ${ }^{2}$ Timo Partonen, ${ }^{3}$ Inkeri Parkkari. ${ }^{1}$ EUPHAnxt, The Netherlands; ${ }^{2}$ University of Helsinki and National Institute for Health and Welfare, Finland; ${ }^{3}$ Finnish Transport Safety Agency, Finland

\subsection{6/injuryprev-2016-042156.53}

Deliberate self-harm has received considerable attention during the last years. Researchers consider it to be a coping strategy used to manage emotional distress and release tension. University students often encounter these feelings. Studies also suggest that self-harm might be more common than previously expected, one study indicating that $14 \%$ of the sample of 500 university students had engaged in self-harm at least once during their lifetime. In addition to self-harm, alcohol impaired driving is also common among university students, and maybe unsurprisingly, driving under the influence of alcohol is one of the main causes of road traffic accidents among young drivers. Such risky and selfdestructive behaviours deserve attention.

The aim of this workshop is to give more insights into the types of injuries young adults and university students in particular are likely to encounter. Two keynote speakers will provide the background for this workshop. Timo Partonen, adjunct professor of Psychiatry at the University of Helsinki and a research professor at National Institute for Health and Welfare, will talk about the ways in which direct and indirect self-harm can be detected and what are the most common risk factors behind these incidents. He will also give suggestions on how to deal with such cases and where to find help. The second speaker, M.Sc. (Psychology) Inkeri Parkkari, Chief Adviser at Finnish Transport Safety Agency, is going to discuss the types of risk factors that contribute to traffic accidents among young people by giving examples of different case studies. She will also address young people's perceptions of the most effective interventions to reduce these casualties. The workshop will provide several opportunities for participants to interact with speakers and with each other.

\section{SUICIDE PREVENTION AMONG ADOLESCENTS AND YOUNG ADULTS}

Timo Partonen. National Institute for Health and Welfare (THL), Finland.

\subsection{6/injuryprev-2016-042156.54}

Background In Finland the suicide mortality has decreased by $51 \%$ from 1990 to 2014 (from 30.0 to 14.6 per 100,000). However, within Finland, there are still disparities in the distribution of deaths from suicide by age, gender and region.

Current activities for suicide prevention among children, adolescents and young adults are, e.g., KiVa school which includes about $90 \%$ of all comprehensive schools in Finland and targets against bullying, Good Hunting Mate! which provides psychosocial support targeted at members of hunting clubs, and Time Out! which provides psychosocial support targeted at men exempted from military or civil service. In addition, the Current Care Guidelines by the Finnish Medical Society DUODECIM which in 2013-2015 have been published for bipolar disorder, borderline personality disorder, depression, eating disorders, insomnia, post-traumatic stress disorder, and schizophrenia support these activities. Further support has been provided by EUGENAS which exchanged the best practices for suicide prevention in 2012-2014 and produced the general and schoolbased guidelines, and the toolkits for the workplace and for media professionals.

The aim of this workshop is to meet and have discussion on problems and suicide prevention measures which target at adolescents and young adults. The most effective interventions to reduce deaths from suicide are also to be discussed.

\section{RISK FACTORS AMONG YOUNG DRIVERS IN FINLAND}

Inkeri Parkkari. Finnish Transport Safety Agency, Finland.

\subsection{6/injuryprev-2016-042156.55}

Background It is commonly known that young drivers, especially male drivers, have a higher risk of being involved in an accident. In Finland, all fatal motor vehicle accidents are investigated indepth by multi-professional Road Accident Investigation Teams. An investigation folder is compiled from each accident and the data is also coded into a fatal accident data base. Members of the investigation teams use standardised investigation forms, which ensures the systematic acquisition of data. Based on this data, the background factors of young male and female driver's accidents differ from each other in several ways, e.g. accident type, time of year, time of week, driving under the influence of alcohol, speeding, previous traffic offences and vehicle characteristics.

The aim of this workshop is to have discussion of the types of risk factors that contribute to road accidents among young people by giving examples of different case studies. The most effective interventions to reduce these casualties are also to be discussed. 


\section{Indigenous Safety}

\section{MON W AP 4}

\section{IMMERSION DEATHS OF INDIGENOUS PEOPLES IN CANADA - EPIDEMIOLOGY, CULTURE, PREVENTION}

${ }^{1}$ Shelley Dalke, 1,2Peter Barss, 'Karlyn Olsen, ${ }^{1} J a n e$ Hamilton. ${ }^{1}$ Canadian Red Cross Water Safety Program; '2Division of Occupational and Environmental Health, School of Population and Public Health, University of British Columbia, Vancouver, Canada

\subsection{6/injuryprev-2016-042156.56}

Background Indigenous peoples in Canada live in a mix of rural and urban areas. Open bodies of water are often essential for subsistence and recreational transport, fishing, and hunting. Death rates are several times higher than nationally. The goal is preventing immersion deaths by implementing evidence-based interventions for main activities and risk factors in culturally appropriate programs.

Methods Annual Red Cross collection of 1991-2010 coroner data by structured questionnaire, including activity, purpose, personal, equipment, environment factors, and trends. Cultural factors pertinent to interventions were assessed by literature reviews, including anthropological surveys. Interventions were developed based upon risk factors for main activities, cultural values, and practical considerations. Logistic regression was used to assess flotation device wearing, controlling for other variables.

Results Surveillance identified 1213 immersion and 27 trauma deaths. Boating, including transport, fishing, and hunting, accounted for 37\% ( $\mathrm{n}=444)$, non-aquatic activities such as walking or playing near water and on ice $21 \%$, aquatic such as swimming or wading $17 \%$, land ice and air transport $17 \%$, bathing 3\%, unknown 6\%. 52\% involved recreation, 34\% daily life/ subsistence, occupational 4\%, rescue $2 \%$, other $1 \%$, unknown $8 \%$. Main risk groups were males $\geq 15$ years, $73 \%$, and $1-4$ year-olds, 9\%. Swimming ability was reported for $26 \%$ of $\geq 5$ years, including 23\% non-swimmers, $12 \%$ weak, $45 \%$ average/ intermediate/unspecified, $6 \%$ strong. Among $\geq 15$ year-olds, alcohol was involved for $\geq 60 \%$ and illegal drugs $\geq 10 \%$. Rivers and current were a factor for 35\%. For 0-9-year-olds, 73\% died without adults. Death rates were similar across Canada, much higher in the North. Boating death rates fell from 4.9 to 1.2/ 100,000/population/year between 1991-1995 and 2006-2010; for other activities, deaths fell during 1991-2000, but not 20012010. Main risks for boating included non-wearing of flotation, with only 5\% wearing; for $40 \%$ none was aboard. Logistic regression showed $68 \%(\mathrm{p}=0.000)$ reduced odds of properly wearing flotation, compared with non-indigernous. Among 0-14year-olds, $44 \%$ of known ethnicity were indigenous, $0 \%$ wearing, others 33\% wearing; no indigenous youth wore PFDs, others $13 \%$. Capsizing, falling overboard, and swamping accounted for $75 \%$. Waves, wind, cold water and other cold factors were frequent. For aquatic activities, 15-40-year-old males were main victims, for non-aquatic $1-4$-year-olds and $\geq 15$ males. Rivers were the most frequent body of water. Ice transport victims were predominantly $\geq 20$-year-old males using snowmobiles, while both males and females $\geq 15$ were victims of on-road into water deaths. Ice transport deaths mainly occurred in central and Prairie Provinces and northern territories. Most road transport immersions were in the Prairies.
Conclusions To avert immersions for all water-related activities, surveillance supports raising ability to swim and to survive in currents, especially for males, and reducing alcohol and illegal drug consumption among adult males. For children, especially 1-4year-olds, constant adult supervision by families, and/or development of community nurseries, are essential. Internationally, mandatory flotation wearing is the most effective boating intervention. During boating and snowmobile travel on ice, wearing of flotation at all times is essential It is encouraged by programs, which need reinforcement by legislation. Cold-protective clothing is frequently essential. Culturally sensitive safety promotion is being implemented and assessed for main activities and risk groups.

\section{DRIVING CHANGE: IMPLEMENTATION OF A MULTI-SITE COMMUNITY LICENSING PROGRAM FOR ABORIGINAL PEOPLE}

1,2 2 atricia Cullen, ${ }^{3}$ Kathleen Clapham, ${ }^{1,2}$ Kris Rogers, ${ }^{1,2}$ Jake Byrne, ${ }^{1,4}$ Kate Hunter, ${ }^{1}$ Serigne Lo, 1,2 Rebecca Ivers. 'The George Institute for Global Health; ${ }^{2}$ Sydney School of Public Health, University of Sydney, Australia; ${ }^{3}$ Australian Health Services Research Institute, the University of Wollongong; ${ }^{4}$ The Poche Centre for Indigenous Health, the University of Sydney

\subsection{6/injuryprev-2016-042156.57}

Background In Australia, Aboriginal and Torres Strait Islander people experience higher rates of injury-related morbidity and mortality relative to the non-Aboriginal population. Aboriginal people are almost three times as likely to die from transportrelated injury and 30\% more likely to sustain serious transportrelated injury. This disparity has been attributed to specific risk factors including unlicensed driving, which is considered to be prevalent in Aboriginal communities and is a significant risk factor for road trauma.

The 'Driving Change' program has been implemented in 12 NSW communities to reduce barriers to licence participation and increase safe and legal driving behaviour. This research presents a mixed-methods process evaluation of 'Driving Change'.

Methods Triangulation of stakeholder interviews $(n=22)$, participant focus groups $(n=18)$ and program data $(n=720)$ collected April 2013 to October 2015. Descriptive and regression analyses of program data (demographics, service delivery and licensing outcomes). Framework analysis of qualitative data to gain a richer understanding of fidelity, dosage and the program context including barriers and facilitators to implementation.

Results Variation in delivery and outcomes between sites was found, but anticipated as the program is intended to adjust to meet local needs rather than be prescriptive. Interviewees reported strong support for the program, however maintaining long-term community engagement emerged as a significant implementation challenge; consequently the program intensified support for local field workers to broker collaborative relationships with communities.

Conclusions Driving Change is meeting community engagement priorities and reaching the target population. This evaluation highlights the value of involving community and government stakeholders to foster capacity building and ensure a culturally acceptable approach to reducing injury and promoting safety within Aboriginal communities. 